
for Mechanical Engineering

\title{
Optimization of Deposition Parameters for MPCVD Diamond Coatings Grown on WC-Co Substrates Using Taguchi and Analytic Hierarchy Process Method
}

\begin{tabular}{|c|c|}
\hline Journal: & Transactions of the Canadian Society for Mechanical Engineering \\
\hline Manuscript ID & TCSME-2020-0148.R1 \\
\hline Manuscript Type: & Article \\
\hline $\begin{array}{r}\text { Date Submitted by the } \\
\text { Author: }\end{array}$ & 07-Dec-2020 \\
\hline Complete List of Authors: & $\begin{array}{l}\text { Jian, Xiaogang; Tongji University } \\
\text { Hu, Jibo; Tongji University } \\
\text { Tang, Jinyao; Tongji University } \\
\text { Ma, Qianli; Tongji University }\end{array}$ \\
\hline Keywords: & $\begin{array}{l}\text { Diamond coating, Parameters optimization, Taguchi method, AHP } \\
\text { analysis }\end{array}$ \\
\hline $\begin{array}{r}\text { Is the invited manuscript for } \\
\text { consideration in a Special } \\
\text { Issue? : }\end{array}$ & Not applicable (regular submission) \\
\hline
\end{tabular}

\section{SCHOLARONE $^{\text {th }}$ \\ Manuscripts}




\title{
Optimization of Deposition Parameters for MPCVD Diamond
}

Coatings Grown on WC-Co Substrates Using Taguchi and Analytic

\section{Hierarchy Process Method}

Xiaogang Jian*, Jibo Hu, Jinyao Tang, Qianli Ma

School of Mechanical Engineering, Tongji University, 201804, Shanghai, PR China

*Corresponding author: jianxgg@tongji.edu.cn

\begin{abstract}
In this study, substrate temperature $(t)$, total pressure $(p)$, methane flow $(M)$ and carbon dioxide flow $(C)$ were considered to deposite diamond coatings on $\mathrm{WC} / \mathrm{Co}(6 \mathrm{wt} . \%)$ substrates under $\mathrm{CH}_{4} / \mathrm{H}_{2} / \mathrm{CO}_{2}$ atmosphere. The Taguchi method and AHP method were used to determine the parameter plan and the sequence of the parameter plan, respectively. The results showed that three schemes with better parameters could be determined through the Taguchi method, the best parameters with $t=750{ }^{\circ} \mathrm{C}, p=6 \mathrm{kPa}, M=7 \mathrm{~mL} / \mathrm{min}$, $C=4 \mathrm{~mL} / \mathrm{min}$ could be choosed based on AHP analysis and the best parameters could be verified through experiment.
\end{abstract}

Keywords: Diamond coating; Parameters optimization; Taguchi method; AHP analysis.

\section{INTRODUCTION}

Diamond coatings are the most important industrial materials which have excellent properties such as chemical inertness, tribological performance, anti-corrosion performance, mechanical, extreme hardness and biocompatibility (Li et al. 2016; Shen et al. 2013; Ali et al. 2004). It is promising material for industrial applications including cutting tools, optical coatings and many other potential applications (Salgueiredo et al. 2013; Zhang et al. 2014). At present, the main materials of common tools, drills, molds and other materials are cemented carbide, and it is a more 
important issue to improve their wear resistance and service life. However, the key problem of depositing diamond coating on cemented carbide substrate is that the bonding strength between the coating and the substrate is low and easy to fall off.

To obtain high-quality and excellent-performance coatings, parameter optimization by chemical vapor deposition (CVD) method is a research direction. Zhang et al. (2014); Wang et al. (2015); Wei et al. (2009) were to study deposition parameters of diamond coatings on WC/Co substrates and achieve a series of research results. An optimum selection of deposition parameters is extremely important. Traditionally, the study of influencing factors belongs to the single factor method. How to analyze the conditions of multi-factors, analyze their weight and importance ranking, some mathematical application methods were applied such as orthogonal experiment method, Taguchi method, harmonic response analysis, analytic hierarchy process, technique for order preference by similarity to an ideal solution and so on.

Due to prepare and obtain a better diamond coating surface quality, mathematical theory research is becoming more and more extensive. Manivel and Gandhinathan (2016) optimized cutting parameters for turning of austempered ductile iron based the Taguchi method. Alberto et al. (2014) used the Taguchi method with multiple performance characteristics in the optimization of optical fibres. Jiang et al. (2016) optimized the growth parameters of diamond films using Response Surface Methodology. De Souza et al. (2018) was based on AHP-TOPSIS-2N (Analytic Hierarchy Process-Technique for Order Preference by Similarity to Ideal Solution) method for decision-making on the multi-objectives of the project portfolio. Zaidan et al. (2020) recruited software programmers from multiple perspectives, in order to save time and get admission results quickly, based on AHP and Group TOPSIS technology for ranking the 
alternatives. Yu et al. (2018) applied AHP process to get the optimal design of weight, power consumption and stiffness. At present, there were many methods to optimize the diamond coating parameters and some results had been achieved. However, they all needed lots of experimental data to analyze the influence of multiple parameters and took lots of time, which lacked a ranking of the importance of influencing factors. Even when little was known about the processes and the mechanisms, the Taguchi method and AHP method were used to analyze the influencing factors to obtain the optimal ranking. Finally, the experiments were carried out for targeted verification and the effect was significant.

In this paper, substrate temperature, total pressure, methane flow and carbon dioxide flow were considered to deposite diamond coatings on WC/Co (6 wt.\%) substrates under $\mathrm{CH}_{4} / \mathrm{H}_{2} / \mathrm{CO}_{2}$ atmosphere. To study the influence of parameters on the diamond coating, the Taguchi method and AHP method were used to determine the parameter plan and the sequence of the parameter plan, respectively. Finally, the best parameters were verified through experiment.

\section{EXPERIMENT}

\subsection{Deposition and characterization}

The diamond-coated substrate was cemented carbide of the WC/Co (Co 6 wt. \%) which the dimensions were $12 \times 12 \times 2 \mathrm{~mm}^{3}$. In order to decrease the content of surface metallic cobalt, pretreatment was required before the diamond coating deposited. (1) Alkaline etching of the Murakami's reagent $\left(\mathrm{K}_{3}[\mathrm{Fe}(\mathrm{CN})]_{6}: \mathrm{KOH}: \mathrm{H}_{2} \mathrm{O}=1: 1: 10\right.$ ) removed part of the WC in the cemented carbide for $30 \mathrm{~min}$, so that the cobalt was exposed and easier to be removed by acid etching;(2) Then the WC-Co substrates were immersed in the Caro's acid $\left(10 \mathrm{~mL} \mathrm{HCl}: 40 \mathrm{~mL} \mathrm{H}_{2} \mathrm{O}_{2}\right)$ at $60{ }^{\circ} \mathrm{C}$ for $30 \mathrm{~s}$ to further etch the cobalt element still existed on the surface;(3) in order to increase the 
nucleation density, grind inganon with $4.5 \pm 0.45 \mu \mathrm{m}$ diamond powder and mechanical scratch substrate for about $30 \mathrm{~min}$.

During experiments, the grown of the diamond films with a $2 \mathrm{~kW}, 2.45$ $\mathrm{GHz}$ microwave plasma chemical vapor deposition (MPCVD) was synthesized. MPCVD devices required rigorous checks before they could be used. After the blow was vacated under a basic vacuum (approximately $0.1 \mathrm{~Pa}$ ), the microwave reaction chamber was first pumped into $200 \mathrm{sccm} \mathrm{H}_{2}(99.999 \%)$. Further cobalt removal could be carried out by $\mathrm{H}_{2}$ plasma etching method, and the sample scanned for 10 minutes. With the addition of $\mathrm{CH}_{4}$ gas and $\mathrm{CO}_{2}$ gas, the total pressure and microwave power needed to be adjusted accordingly. What's more, the gas should be fully blended that was mixture gas before input to the chamber. After the mixture gas was completely stable, deposition duration was determined at 10 hours. The infrared thermometer detected the substrate temperature through the observe window (about 1 meter in height) for coating deposition. The parameters used to prepare the diamond coating orthogonal experiment are shown in Table 1. The deposition experiments of four factors three levels conducted based on the Taguchi method (Salgueiredo et al. 2011). Four deposition parameters including $t, p, M$ and $C$ were defined as factors.

Table 1. $L 9$ orthogonal experiment four factors three levels.

\begin{tabular}{cccc}
\hline Factors & \multicolumn{3}{c}{ Levels } \\
\cline { 2 - 4 } & 1 & 2 & 3 \\
\hline$t /{ }^{\circ} \mathrm{C}$ & 650 & 700 & 750 \\
$p / \mathrm{kPa}$ & 6.0 & 7.5 & 9.0 \\
$M /\left(\mathrm{mL} \cdot \mathrm{min}^{-1}\right)$ & 5 & 6 & 7 \\
$\mathrm{C} /\left(\mathrm{mL} \cdot \mathrm{min}^{-1}\right)$ & 4 & 6 & 8 \\
\hline
\end{tabular}

As presented in Table 2, Taguchi array of deposition conditions and analytical results were listed. Scanning electron microscopy (SEM, S$2360 \mathrm{~N}$, HITACHI, Japan) was used to detect the surface morphology and crystal grain size of the diamond coating, and the magnification allows the naked eye to observe the micro-nano-level surface morphology. Raman 
(LabRam HR Evolution, HORIBA, Japan), through $632 \mathrm{~nm} \mathrm{He-Cd} \mathrm{laser,}$ showed different spectral peaks on the sample surface. The adhesion between the substrate and the film could be qualitatively evaluated by the indentation morphology of Rockwell indentation tests (HR-150A).

Table 2. Experimental layout using $L\left(3^{4}\right)$ deposition parameters and results.

\begin{tabular}{cccccccc}
\hline Sample No. & $t /{ }^{\circ} \mathrm{C}$ & $p / \mathrm{kPa}$ & $M /\left(\mathrm{mL} \cdot \mathrm{min}^{-1}\right)$ & $C /\left(\mathrm{mL} \cdot \mathrm{min}^{-1}\right)$ & $v /\left(\mu m \cdot h^{-1}\right)$ & $Q$ & $\sigma / \mathrm{GPa}$ \\
\hline I & 1 & 1 & 1 & 2 & 1.00 & 1.00 & 0.27 \\
II & 1 & 2 & 2 & 1 & 0.94 & 1.21 & 0.28 \\
III & 1 & 3 & 3 & 3 & 0.94 & 1.55 & 0.27 \\
IV & 2 & 1 & 2 & 3 & 2.04 & 1.07 & 0.27 \\
V & 2 & 2 & 3 & 1 & 0.82 & 1.33 & 0.38 \\
VI & 2 & 3 & 1 & 2 & 1.02 & 1.02 & 0.33 \\
VII & 3 & 1 & 3 & 2 & 0.94 & 1.10 & 0.29 \\
VIII & 3 & 2 & 1 & 3 & 1.08 & 1.05 & 2.10 \\
IX & 3 & 3 & 2 & 1 & 0.74 & 0.99 & 0.29 \\
\hline
\end{tabular}

\subsection{Experimental Design and Statistical Analysis}

AHP calculation steps:

Step 1: Building a hierarchical model.

According to the relationship between them, the object layer, criterion layer and scheme layer of decision-making were defined into the three layers. And a hierarchical structure diagram was drawn in Fig. 1.
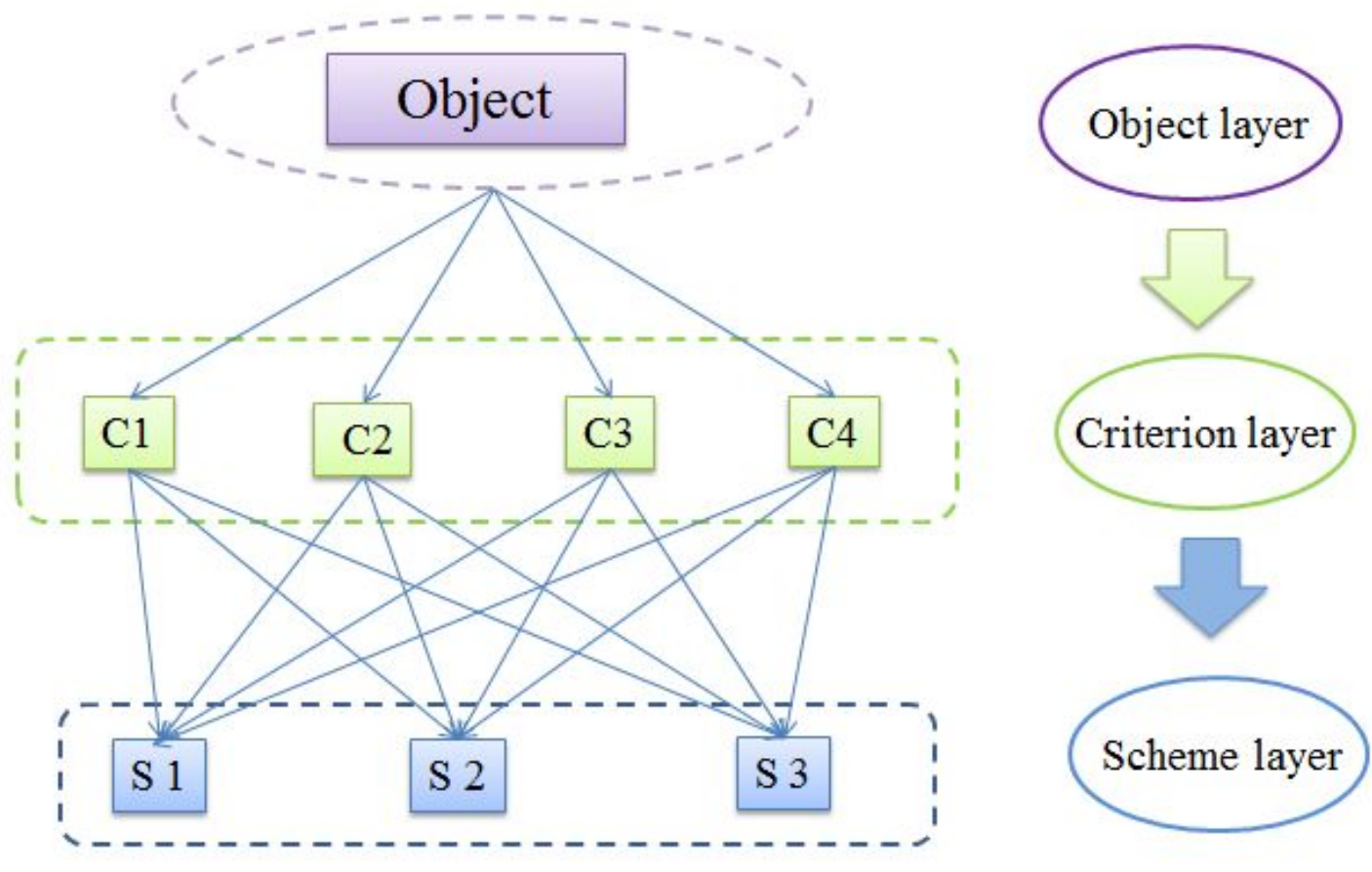

Fig. 1. AHP-hierarchy structure. 
Step 2: Pairwise comparison matrix.

Establish the influence matrix of related factors as represented in eq. (1) and identify the importance ranking of related factors in Wind and Saaty (1980).

$$
A=\left(\begin{array}{ccc}
x_{11} & \square & x_{1 n} \\
\square & \square & \square \\
x_{n 1} & \square & x_{n n}
\end{array}\right) \text { where, }\left\{\begin{array}{l}
x_{i j}=1 \\
x_{j i}=\frac{1}{x_{i j}}
\end{array}\right.
$$

Step 3: Consistency test.

1. Calculate the normalization of each column of the judgment matrix A.

$$
\begin{aligned}
& \left\{\begin{array}{l}
\varpi_{i j}=\frac{a_{i j}}{\sum_{i=1}^{n} a_{i j}} \\
w_{i}=\sum_{j=1}^{n} \varpi_{i j} \\
W_{i}=\frac{w_{i}}{\sum_{i=1}^{n} w_{i}}
\end{array}\right. \\
& W=\left(w_{1}, w_{2}, \square, w_{n}\right)^{T}
\end{aligned}
$$

2. Calculate the maximum feature value approximation.

$$
\lambda_{\max }=\sum_{i=1}^{n} \frac{(A W)_{i}}{n W_{i}}
$$

3. Consistency index.

$$
\left\{\begin{array}{l}
\text { C.I. }=\frac{\lambda_{\max }-n}{n-1} \\
\text { C.R. }=\frac{\text { C.I. }}{\text { R.I. }}
\end{array}\right.
$$

Where $n$, C.I., R.I. C.R., $\lambda_{\max }$ of the judgment matrix are the order, the coincidence indicator, the average random consistence indicator (Yu et al. 2018), the random consistence ratio and the maximum value of the matrix eigenvalue, respectively. If it is $<10 \%, C . R$. is acceptable (Sherekar and Tatikonda 2016). And if not, then the comparisons need to modify. 
Step 4: Hierarchical total ranking and decision.

Determine the ranking of the relative importance and the influencing factors of each layer to the overall goal in Table 3.

Table 3. Hierarchical total order.

\begin{tabular}{cccccc}
\hline$C$ & $C_{1}$ & $C_{2}$ & $\cdots$ & $C_{\mathrm{m}}$ & $V_{\mathrm{i}}=S \times C$ \\
\cline { 2 - 5 } & $w_{1}$ & $w_{2}$ & $\cdots$ & $w_{\mathrm{m}}$ & \\
\cline { 1 - 5 }$S_{1}$ & $v_{11}$ & $v_{12}$ & $\cdots$ & $v_{1 \mathrm{~m}}$ & $V_{1}=\sum_{i=1} w_{j} v_{1 j}$ \\
$S_{2}$ & $v_{21}$ & $v_{22}$ & $\cdots$ & $v_{2 \mathrm{~m}}$ & $V_{2}=\sum_{i=1}^{\sum} w_{j} v_{2 j}$ \\
$\vdots$ & $\vdots$ & $\vdots$ & $\ddots$ & $\vdots$ & $\vdots$ \\
$S_{\mathrm{n}}$ & $v_{\mathrm{n} 1}$ & $v_{\mathrm{n} 1}$ & $\cdots$ & $v_{\mathrm{nm}}$ & $V_{3}=\sum_{i=1} w_{j} v_{n j}$ \\
\hline
\end{tabular}

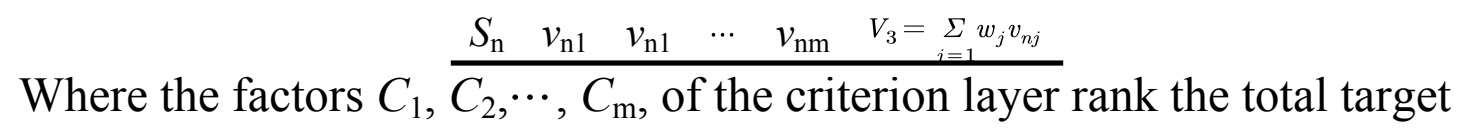
object layer as (feature vector) is $W=\left(w_{1}, w_{2}, \cdots, w_{n}\right)^{T}$;

The $n$ factors of the scheme layer rank the single factor $C_{\mathrm{j}}$ in the upper layer criterion layer as (feature vector) is $v_{1 j}, v_{2 j}, \cdots, v_{n j}(j=1,2, \cdots, m)$; The total ranking of the scheme layer is that the weight of the i-th factor of the object layer to the total target is $\sum_{i=1}^{m} w_{j} v_{i j}$.

\section{RESULTS AND DISCUSSION}

\subsection{Characterization}

The pattern characterization was magnified 2000 times and the morphology of the sample could be clearly observed in Fig. 2. At $650{ }^{\circ} \mathrm{C}$, in Fig. 2a, 2b, and $2 \mathrm{c}$, the morphology of the diamond coatings was basically clear and there were a large number of secondary nucleation, indicating that the energy of the system was low and it could not provide enough energy for the continuous growth of diamond. From Fig. $2 \mathrm{~d}, 2 \mathrm{e}$, and $2 \mathrm{f}$, at $700{ }^{\circ} \mathrm{C}$, the grain size changed from small to large, that was, the trend of changing from fine crystal diamond, microcrystalline diamond (100) and microcrystalline diamond (111). At $750{ }^{\circ} \mathrm{C}$, the diamond coating had a vague shape and severe etching in Fig. $2 \mathrm{~g}, 2 \mathrm{~h}$, and $2 \mathrm{i}$. It showed that the system energy was large, the etching group $\mathrm{H}$ ions and $\mathrm{O}$ ions were active and the diamond 
surface was seriously etched. It was still necessary to optimize the parameters in order to obtain the best diamond coating.

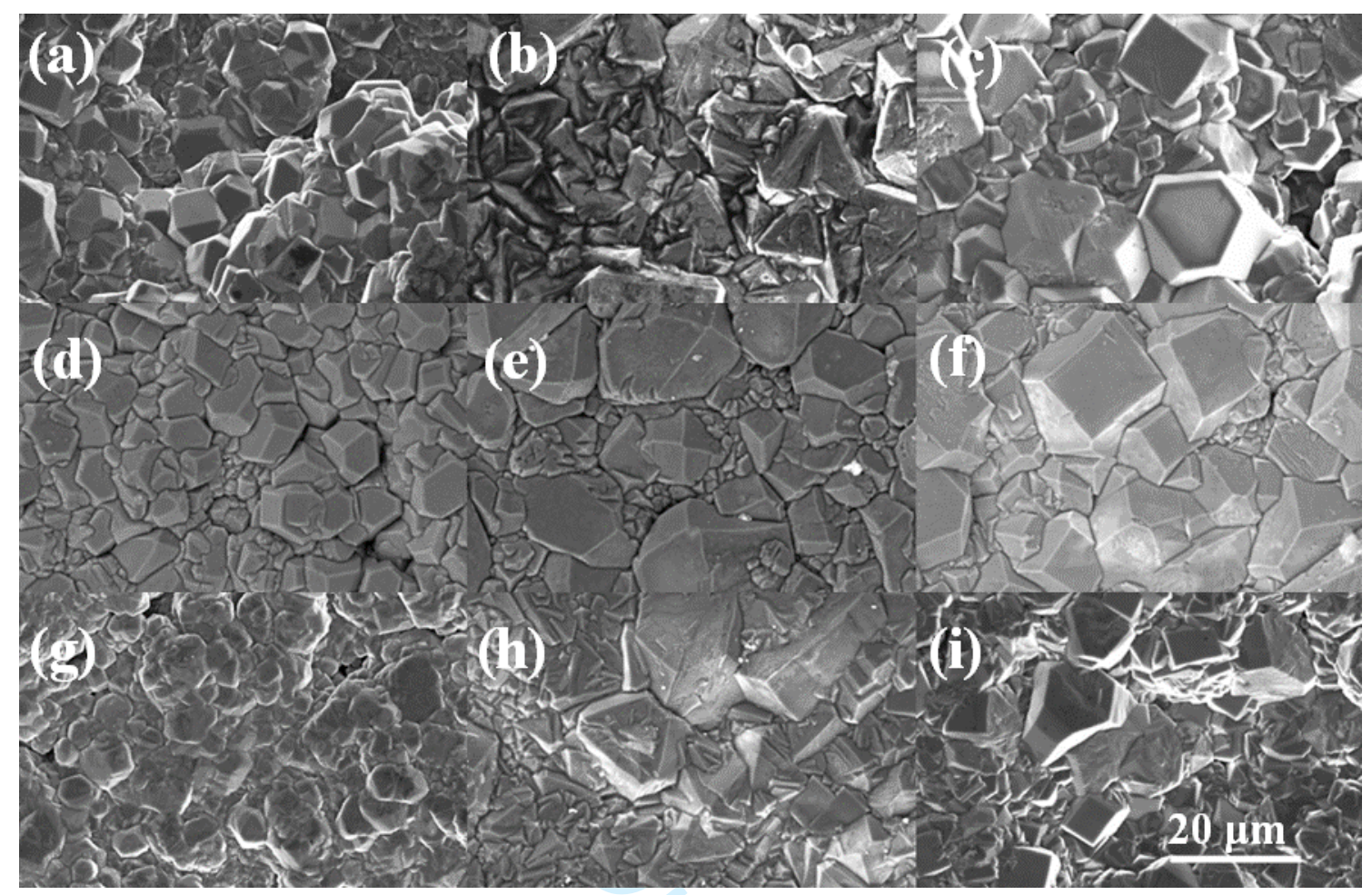

Fig. 2. The SEM photographs of morphologies : (a) I ; (b) II ; (c) III; (d) IV; (e) V; (f)

$$
\text { VI; (g) VII; (h) VIII; (i) IX. }
$$

The Rockwell indentation method was used to detect the adhesion between the film and the substrate: the top angle of the diamond indenter was $120^{\circ} \pm 15^{\prime}$, the top corner radius was $0.1 \pm 0.01 \mathrm{~mm}$ and the load was $980 \mathrm{~N}$. The greater the residual stress, the greater the damage area of the film surface. However, the shedding area of the film was small and the film rupture mainly occurred around the indentation, indicating the good adhesion between the film and the substrate. As shown in Fig. 3a-d, the corresponding diamond coating crack diameters were $0.81,0.63,0.56$ and $0.74 \mathrm{~mm}$, respectively. Figure 3a showed that the diamond coating had smaller grains,contained more non-diamond components and emerged the larger cracks; Figure 3c showed that the diamond coating had larger grain sizes, smaller cracks and no obvious radial cracks. It showed that the appropriate deposition temperature and methane concentration were 
beneficial to the deposition of high-quality diamond coatings and it was necessary to continue to optimize to obtain high-quality coatings.

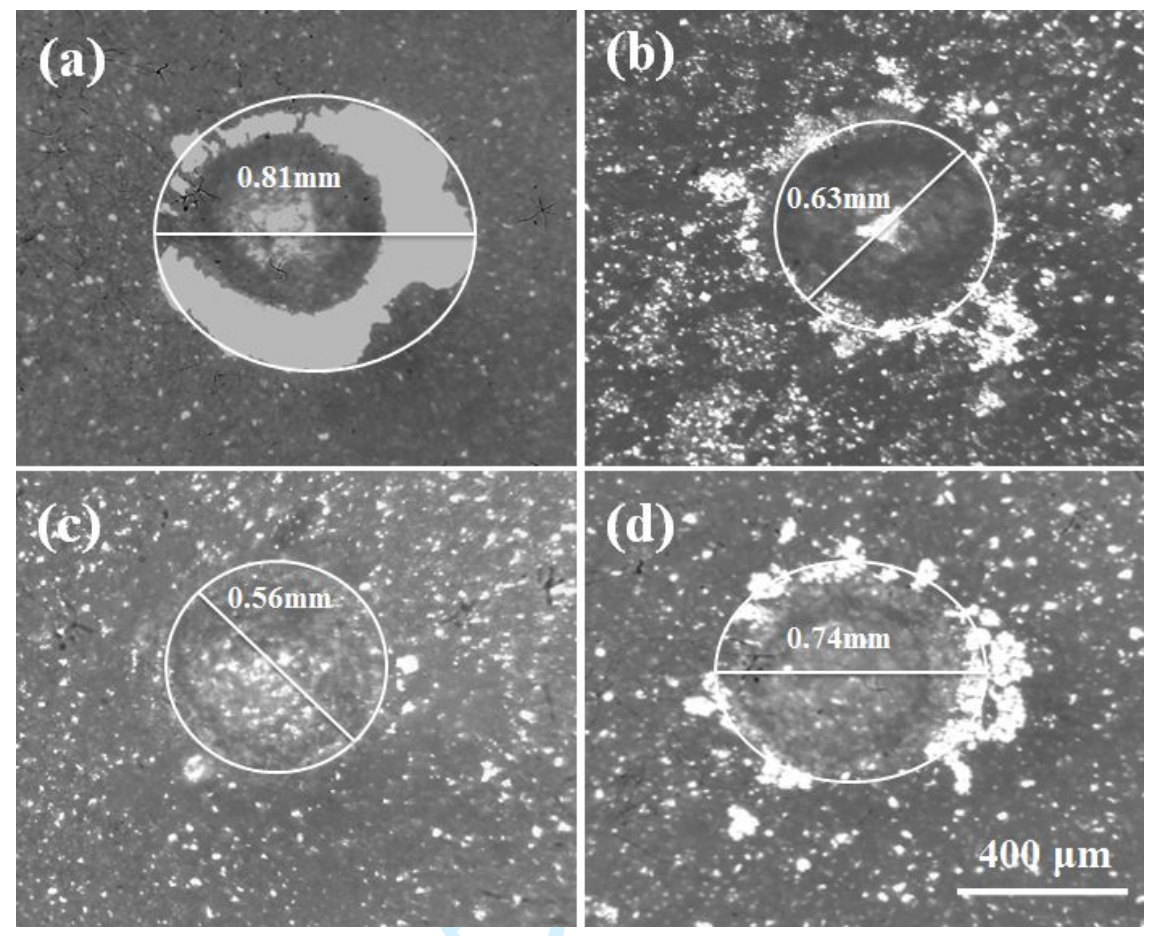

Fig. 3. Indentation morphologies of diamond films: (a) I ;(b) III;(c) VI; (d) VIII. All deposited experiments of the obtained spectra was presented in Fig. 4 and Fig. 5. Raman spectra of diamond films had taken at test points on (a) samples II ( II , represented Raman's original curve and showed in black) and the PL background signal (Y1, reproduced with apolynomial function and shown in red);(b) has been subtracted to yield the Raman spectra which were then fitted using six Lorentzian functions. The representative spectra and corresponding peaks were all shown in Fig. 5, where the obtained Raman data were the Raman spectra after the Y1 baseline subtraction; the Raman-fitting was the Raman spectra after the L fitting; AS was the fitted peak of the amorphous $\mathrm{sp}^{3}$ phase; DIA was the diamond phase; TP was the trans-polyacetylene; $\mathrm{G}$ was the graphitic band; D was the disordered carbon band.

The characteristic peak was shifted from the diamond standard $1332 \mathrm{~cm}^{-1}$, which was caused by the internal stress of the film. Due to the different 
coefficients of thermal expansion between the base material and the diamond, residual stress accumulated, resulting in lattice distortion and shifting of the diamond peak. The characteristic peaks between $1450 \mathrm{~cm}^{-1}$ and $1600 \mathrm{~cm}^{-1}$ showed $\mathrm{sp}^{2}$ structure of non-diamond carbon phase structure. Since the sensitivity of $\mathrm{sp}^{2}$ structure to Raman spectrum was about 50 times higher than that of $\mathrm{sp}^{3}$ structure, it indicated that the film was dominated by diamond. There were a large number of other characteristic peaks of nondiamond structure in the Fig. 5. The characteristic peaks between $1400 \mathrm{~cm}^{-}$ ${ }^{1}$ and $1500 \mathrm{~cm}^{-1}$ were graphite phase $\left(\mathrm{sp}^{2}\right)$ structure, because the diamond film contained other carbon phase structures with higher composition. The D peak of the graphite structure appeared at $1480 \mathrm{~cm}^{-1}$. The characteristic peaks between $1500 \mathrm{~cm}^{-1}$ and $1600 \mathrm{~cm}^{-1}$ were the graphite peak (G peak), indicated that the diamond film contained a large number of nano-sized particles. The characteristic peak between $1100 \mathrm{~cm}^{-1}$ and $1300 \mathrm{~cm}^{-1}$ was the trans-polyacetylene, and the diffusion and aggregation of $\mathrm{H}$ in the film was the main reasons. In Fig. 5c-d, the diamond peak was much sharper in all test data, which showed $1332.18 \mathrm{~cm}^{-1}$ and $1333.25 \mathrm{~cm}^{-1}$, respectively. In Fig. 5f, there also had the trans-polyacetylene and graphite $\left(\mathrm{sp}^{2}\right)$ structure which are corresponding to the band at $1450.16 \mathrm{~cm}^{-1}$ and $1580.26 \mathrm{~cm}^{-1}$ (Yang et al. 2001). What was more, peak at $\sim 1265.93 \mathrm{~cm}^{-1}$ in Fig. $5 \mathrm{~g}$ was ascribed to the amorphous $\mathrm{sp}^{3}$-bonded carbon and peak at $\sim 1171.05 \mathrm{~cm}^{-1}$ in Fig. 5i was presented the trans-polyacetylene. Based on Raman data, two indicators of coating quality and residual stress were obtained, which provided a prerequisite for better analysis of coatings. 

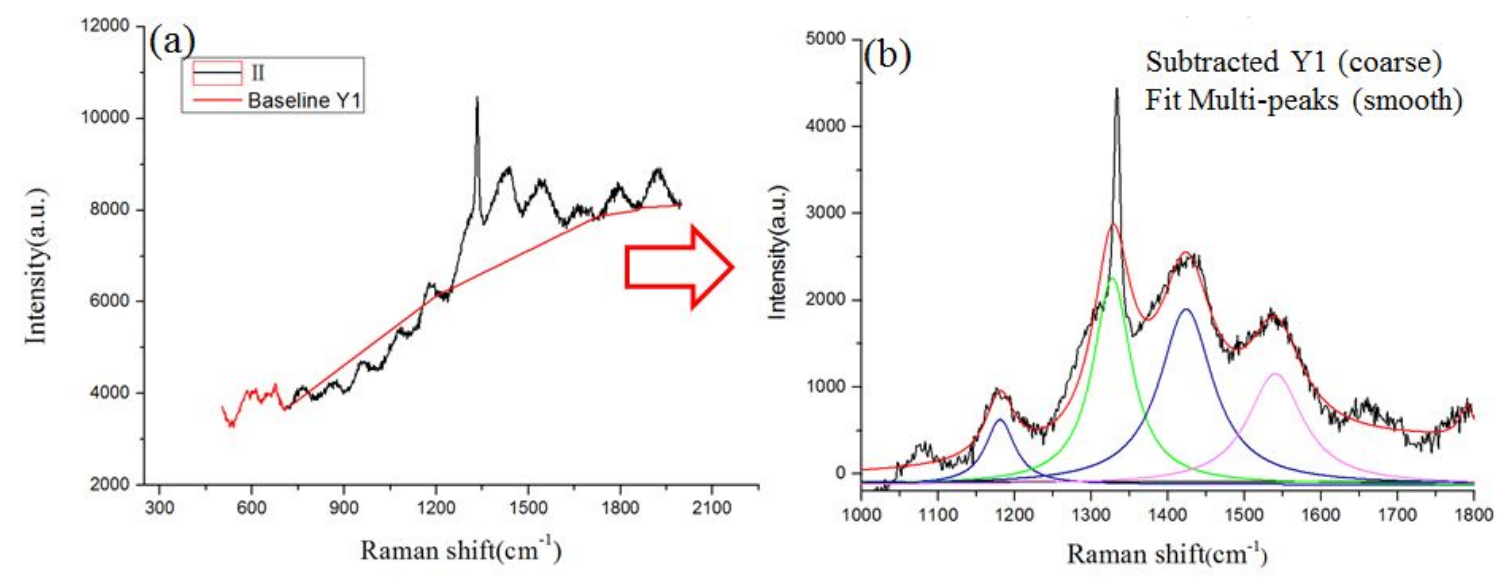

Fig. 4. Raman spectra of diamond films taken at test points on: (a) samples II (Raman's original curve and showed in black) and the PL background signal (Y1, reproduced with apolynomial function and shown in red);(b)has been subtracted to yield the Raman spectra which are then fitted using six Lorentzian functions.
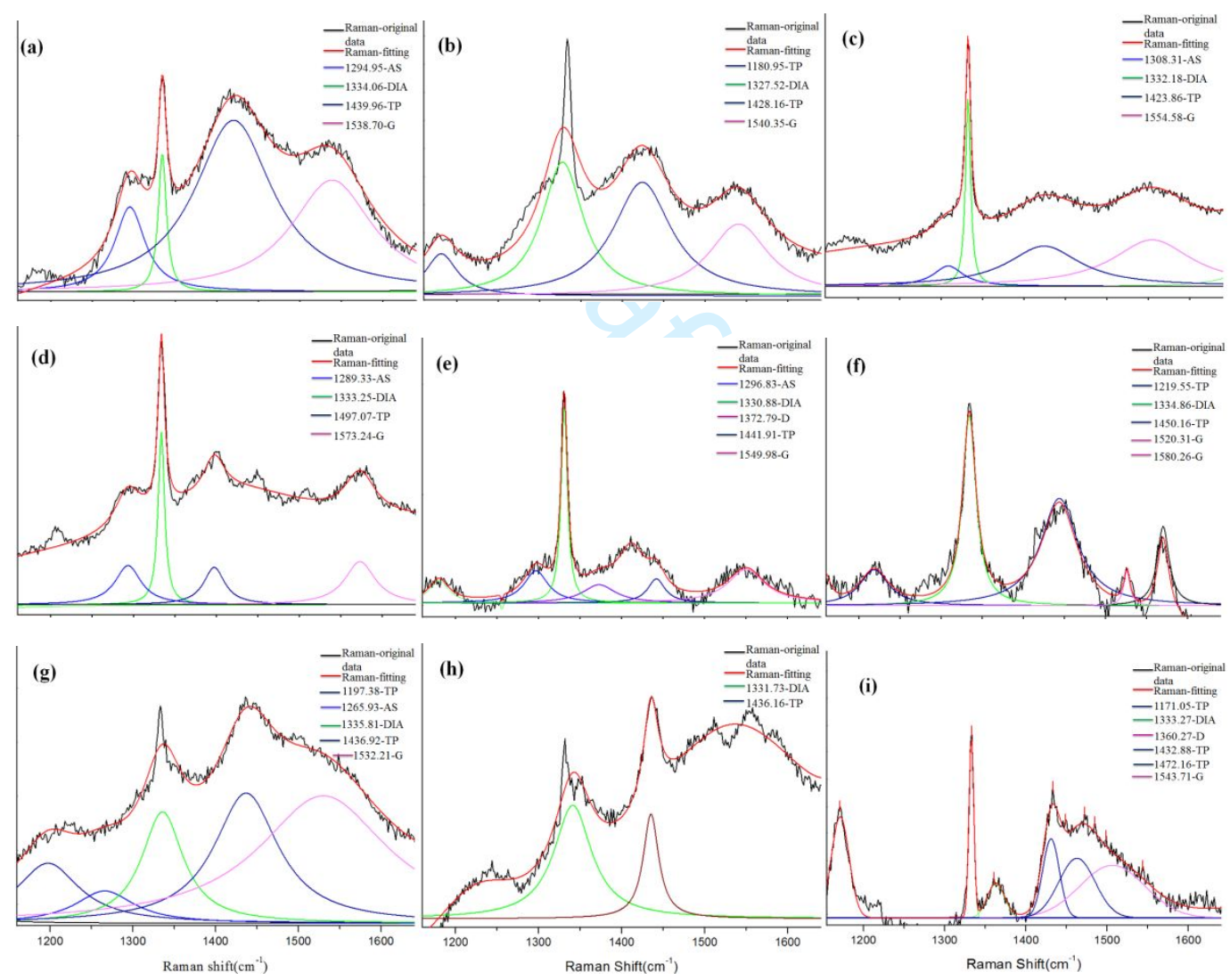

Fig. 5. Raman spectra of as-deposited diamond films with same thickness $(\sim 20 \mu \mathrm{m})$ :

(a) I ; (b) II ; (c) III; (d) IV; (e) V; (f)VI; (g) VII; (h) VIII; (i) IX.

\subsection{Optimisation of the diamond films}

According to SEM and Raman spectroscopy analysis, the analysis results of growth rate, coating quality and residual stress were shown in Table 2. 
The thickness of the coating was measured by an average of five points with the spiral micrometer $(1 \mu \mathrm{m})$. The coating growth rate was approximately equal to the coating thickness divided by the deposition time. The quality of the diamond coating through Raman spectrum was shown by Eq. 5, where $I_{\mathrm{D}}$ was the diamond peak and $I_{\mathrm{G}}$ was the graphite peak (Sails et al. 1996).

$$
Q=\frac{I_{D}}{I_{G}}
$$

The residual stress in diamond coating could pass through the position of diamond peaks in Raman spectroscopy and the natural non-residual diamond peak position of internal stress pure diamond $\left(1332.2 \mathrm{~cm}^{-1}\right)$ to calculate the gap between the Raman frequency shift (Ferreira et al. 2002). Raman frequency shift to a smaller numerical direction offset, there was residual tensile stress in the surface diamond coating. The residual stress values could be calculated by Eq. (6):

$$
\sigma=-0.567 \Delta v\left(\mathrm{~cm}^{-1}\right)
$$

Where: $\sigma$ is the fracture strength determined the residual stress; $\Delta \nu$ is the offset of Raman displacement.

The growth rate was correspondent to the three deposition temperature which was calculated as follows:

\begin{tabular}{ll}
\hline Level 1: $650{ }^{\circ} \mathrm{C}$ & $(0.94+1.08+0.74) / 3=0.92$ \\
Level 2: $700{ }^{\circ} \mathrm{C}$ & $(2.04+0.82+1.02) / 3=1.30$ \\
Level 3: $750{ }^{\circ} \mathrm{C}$ & $(1.00+0.94+0.94) / 3=0.96$ \\
\hline
\end{tabular}

In order to obtain high growth rate, good coating quality and small residual stress, used Taguchi method to process the data in Table 4 and the data change trend in Figure 5.

Table 4. L9 $\left(3^{4}\right)$ Taguchi array of analysis results.

\begin{tabular}{ccccc}
\hline Level & $t /{ }^{\circ} \mathrm{C}$ & $p / \mathrm{kPa}$ & $M /\left(\mathrm{mL} \cdot \mathrm{min}^{-1}\right)$ & $C /\left(\mathrm{mL} \cdot \mathrm{min}^{-1}\right)$ \\
\hline 1 & 0.96 & 1.33 & 0.85 & 1.24 \\
\hline
\end{tabular}




\begin{tabular}{llllll}
\hline & 2 & 1.29 & 0.95 & 0.97 & 0.83 \\
& 3 & 0.92 & 0.90 & 1.35 & 1.03 \\
& $\mathrm{~K}$ & 0.38 & 0.43 & 0.50 & 0.34 \\
& 1 & 1.05 & 1.06 & 1.33 & 1.22 \\
& 2 & 1.14 & 1.20 & 1.02 & 1.11 \\
& 3 & 1.25 & 1.19 & 1.09 & 1.11 \\
& $\mathrm{~K}$ & 0.20 & 0.14 & 0.31 & 0.11 \\
& 1 & 0.89 & 0.28 & 0.48 & 0.88 \\
$\sigma$ & 2 & 0.49 & 1.08 & 0.90 & 0.48 \\
& 3 & 0.27 & 0.30 & 0.28 & 0.30 \\
& $\mathrm{~K}$ & 0.62 & 0.80 & 0.61 & 0.58 \\
\hline
\end{tabular}

Based on these assumptions in Table 4 and Figure 5, the primary and secondary order of factors under each index for $v$ was $M>p>t>C$ through range chart analysis. According to the average of different levels of each index, determining the optimal level combination of each factor was $t_{2} p_{1} M_{3} C_{1}$. The influence trend and primary and secondary order of $Q$ and $\sigma$ were showed as $M>t>p>C$ and $p>t>M>C$, respectively. Optimization plan of $Q$ and $\sigma$ was $t_{3} p_{2} M_{1} C_{1}$ and $t_{3} p_{1} M_{3} C_{3}$, respectively.

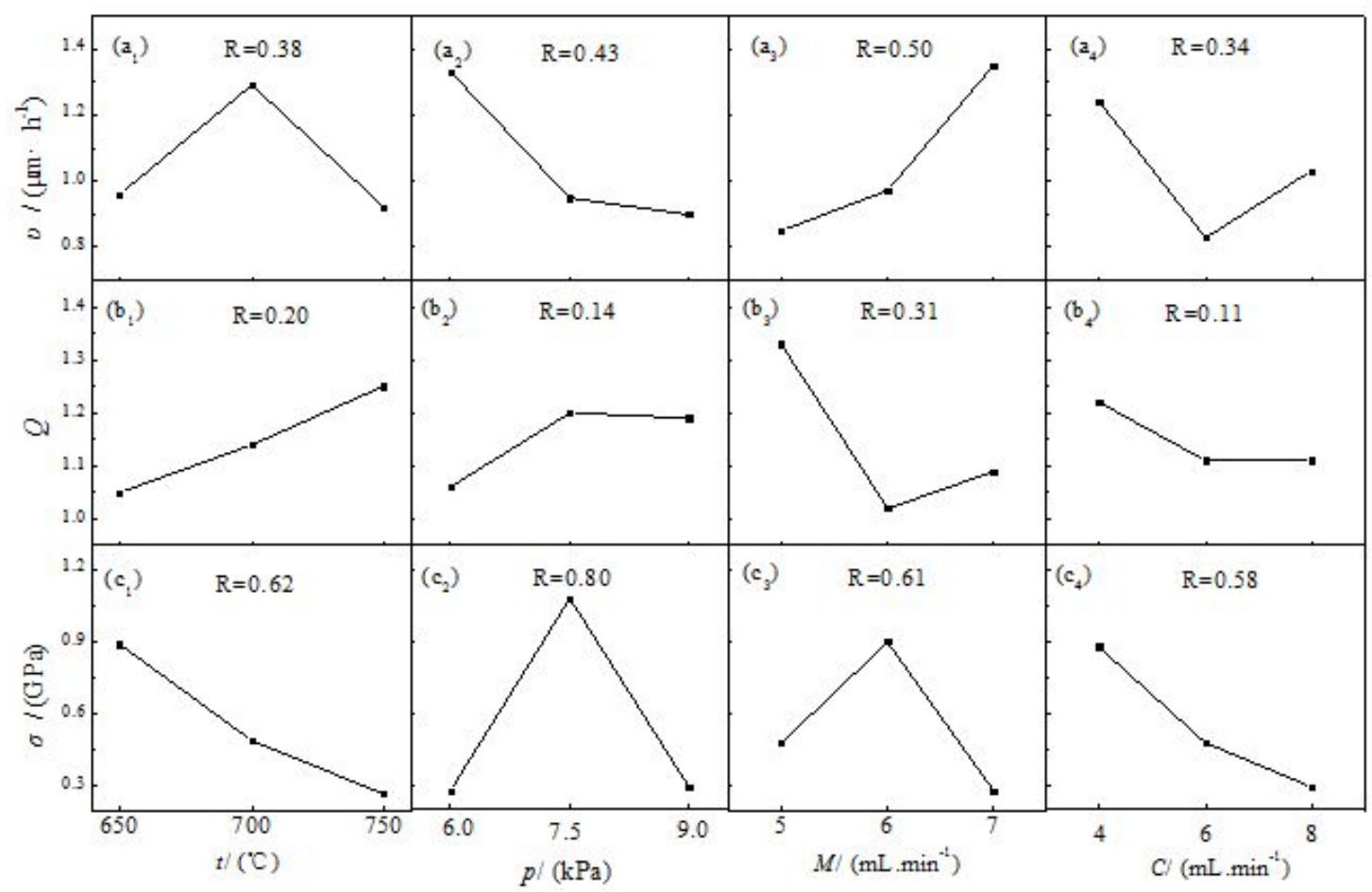

Fig. 6. Variance trend on the growth rate $(v)$, diamond quality factor $(Q)$ and total residual stress $(\sigma)$.

\subsection{AHP method}

Step 1: Building a hierarchical model. 
The object layer to make sure the goal was the optimal deposition parameters. The criterion layer was affected by four factors to achieve this goal, including temperature pressure, methane content and carbon dioxide content. The scheme layer included three plans, which were scheme 1 $\left(t_{2} p_{1} M_{3} C_{1}\right)$, scheme $2\left(t_{3} p_{2} M_{1} C_{1}\right)$, scheme $3\left(t_{3} p_{1} M_{3} C_{3}\right)$ in order.

Development of hierarchy structure was shown in Fig. 5.

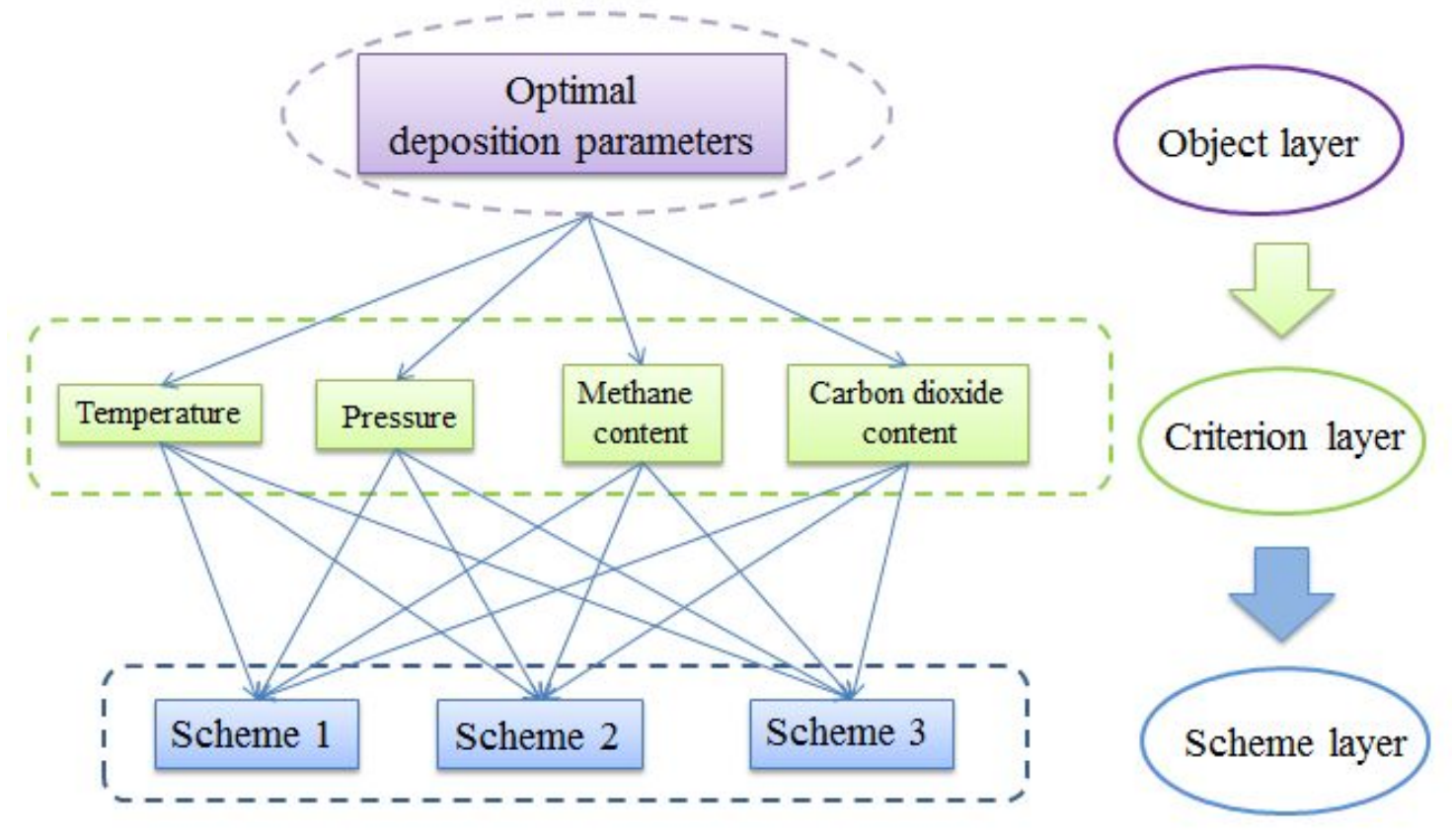

Fig.7. Hierarchical design based AHP.

Step 2: Pairwise comparison matrix.

Calculated the normalization of each column of the judgment matrix.

Construct the judgment matrix by eq. (1).

$$
\begin{aligned}
A & =\left[\begin{array}{cccc}
1 & 5 & 7 & 3 \\
1 / 5 & 1 & 3 & 1 / 3 \\
1 / 7 & 1 / 3 & 1 & 1 / 5 \\
1 / 3 & 3 & 5 & 1
\end{array}\right] \\
C_{1} & =\left[\begin{array}{ccc}
1 & 1 / 3 & 1 / 8 \\
3 & 1 & 1 / 3 \\
8 & 3 & 1
\end{array}\right] C_{2}=\left[\begin{array}{ccc}
1 & 2 & 5 \\
1 / 2 & 1 & 2 \\
1 / 5 & 1 / 2 & 1
\end{array}\right] \\
C_{3} & =\left[\begin{array}{ccc}
1 & 1 & 3 \\
1 & 1 & 3 \\
1 / 3 & 1 / 3 & 1
\end{array}\right] C_{4}=\left[\begin{array}{ccc}
1 & 3 & 4 \\
1 / 3 & 1 & 1 \\
1 / 4 & 1 & 1
\end{array}\right]
\end{aligned}
$$


Step 3: Consistency test.

1. According to eq. (2), the calculation was $W_{A}=\left(\begin{array}{llll}0.558, & 0.122, & 0.057, & 0.263\end{array}\right)^{T}$.

2. Calculated the maximum feature value approximation by eq. (3).

$$
\lambda_{\max }=\frac{2.356}{4 \times 0.558}+\frac{0.492}{4 \times 0.122}+\frac{0.230}{4 \times 0.057}+\frac{1.100}{4 \times 0.263}=4.11815
$$

3. Consistency index by eq. (4).

$$
\left\{\begin{array}{l}
\text { C.I }=\frac{4.11815-4}{4-1}=0.0393833 \\
\text { C.R. }=\frac{0.0393833}{0.89}=0.0442509
\end{array}\right.
$$

If C.R. $<0.1$, within the allowable range, meet the requirements. By analogy calculation, the weight vectors of other matrices could be obtained. The weights were as follows:

$$
\begin{aligned}
& \omega_{A}=\left(\begin{array}{llll}
0.558, & 0.122, & 0.057, & 0.263
\end{array}\right)^{T} \\
& \omega_{C_{1}}=\left(\begin{array}{lll}
0.082, & 0.244, & 0.674
\end{array}\right)^{T} \\
& \omega_{C_{2}}=\left(\begin{array}{lll}
0.606, & 0.265, & 0.129
\end{array}\right)^{T} \\
& \omega_{C_{3}}=\left(\begin{array}{lll}
0.429, & 0.429, & 0.143
\end{array}\right)^{T} \\
& \omega_{C_{4}}=\left(\begin{array}{lll}
0.636, & 0.185, & 0.179
\end{array}\right)^{T}
\end{aligned}
$$

Step 4: Hierarchical total ranking and decision.

The total order of the three levels of scheme 3 was 1 in Table 5 and scheme 3 was the best optimization scheme.

Table 5. Hierarchical total order.

\begin{tabular}{lllllll}
\hline $\mathrm{C}$ & $C_{1}$ & $C_{2}$ & $C_{3}$ & $C_{4}$ & $V_{\mathrm{i}}$ & Rank \\
\cline { 2 - 6 }$S$ & 0.558 & 0.122 & 0.057 & 0.263 & & \\
\hline$S_{1}$ & 0.082 & 0.606 & 0.429 & 0.636 & 0.311 & 2 \\
$S_{2}$ & 0.244 & 0.265 & 0.429 & 0.185 & 0.242 & 3 \\
$S_{3}$ & 0.674 & 0.129 & 0.143 & 0.179 & 0.447 & 1 \\
\hline
\end{tabular}

\subsection{Confirmation test}

Analyzed the three schemes by AHP and got scheme 3 as the best plan. The best process parameter was $t_{3} p_{1} M_{3} C_{3}$, which was $750{ }^{\circ} \mathrm{C}, 6 \mathrm{kPa}, 7 \mathrm{~mL} / \mathrm{min}$, $8 \mathrm{~mL} / \mathrm{min}$. In order to prove the optimized parameters, necessary experimental verification was necessary. Figure 8a showed the typical 
SEM image of diamond film, preferential [100] and [110] orientation, better polycrystalline structure. By estimating the thickness, growth rate of the diamond coating could reach $1.3 \mu \mathrm{m} / \mathrm{h}$. The indentation morphology presented in Figure $\mathbf{8 b}$ that the crack was small and the maximum crack diameter was $0.45 \mathrm{~mm}$ because of the better deposition quality. Figure $8 \mathrm{c}$ showed the Raman property of diamond coating, where quality of diamond film was significantly improved, $1331.17 \mathrm{~cm}^{-1}$ was the sharpest peak, together with some other peaks, such as at $1429.15 \mathrm{~cm}^{-1}, 1490.12 \mathrm{~cm}^{-1}$ and $1564.31 \mathrm{~cm}^{-1}$. The peak at $\sim 1429.15 \mathrm{~cm}^{-1}$ and $\sim 1490.12 \mathrm{~cm}^{-1}$ features to the trans-polyacetylene segments were likely to be concentrated at grain boundaries. And a band centered at approximately $1564.31 \mathrm{~cm}^{-1}$ (G band) was resultant of the graphite deposited during the coating process, indicated that the diamond film contained a large number of nano-sized particles. Compared with the diamond peak $\left(\sim 1332 \mathrm{~cm}^{-1}\right)$, the impurity peak appeared weaker, indicating that the quality of the diamond coating was relatively good. Through experimental verification, we could obtain diamond film with better deposition quality.

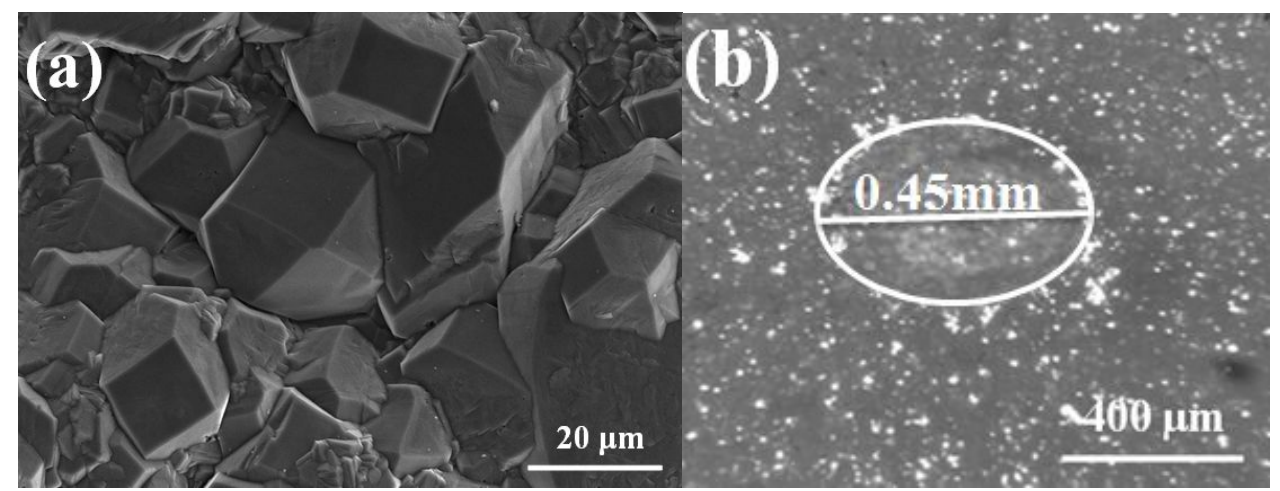




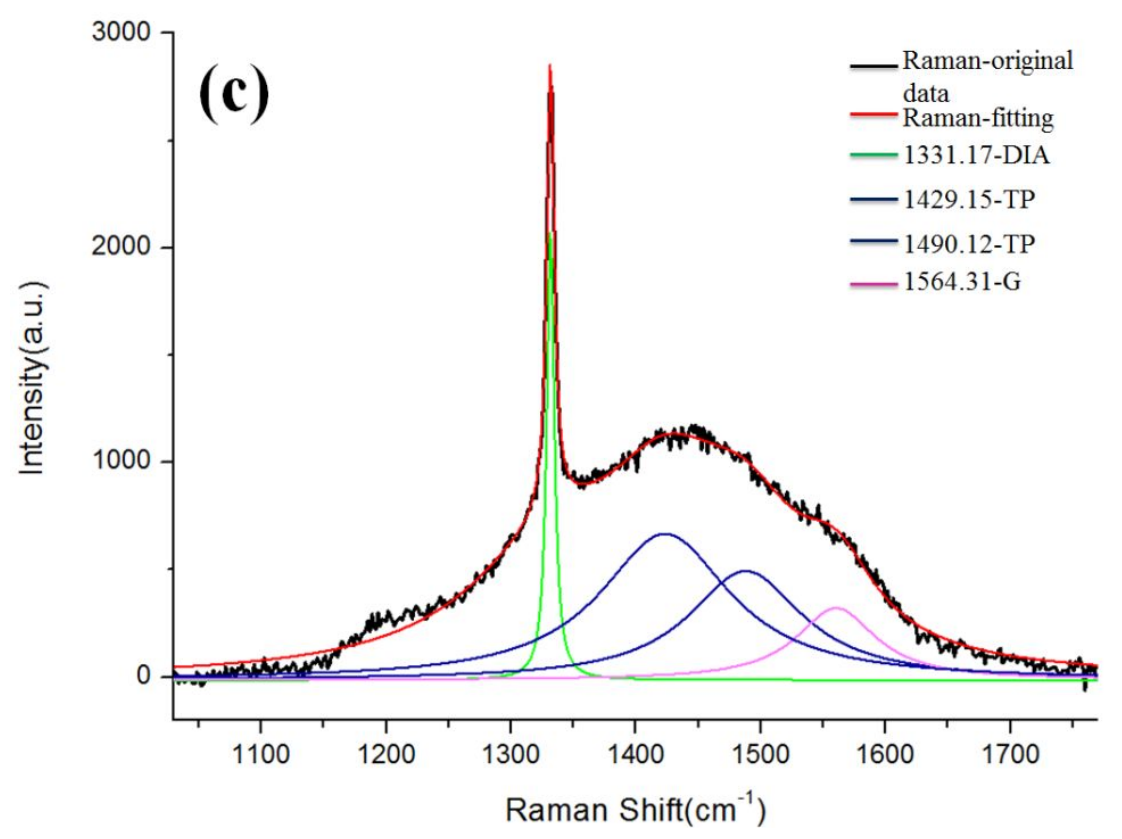

Fig. 8. Confirmation test:(a) SEM image; (b) Indentation morphology; (c) Raman spectra.

\section{CONCLUSION}

In the current work, parameter optimizations were demonstrated with $\mathrm{CH}_{4} / \mathrm{H}_{2} / \mathrm{CO}_{2}$ atmosphere. To analyze multiple influencing parameters by the Taguchi and AHP method, three conclusions were as follows. Based on the maximum growth rate, the best coating quality and minimum residual stress, obtained three better deposition process parameters: $t_{2} p_{1} M_{3} C_{1}$, $t_{3} p_{2} M_{1} C_{1}, t_{3} p_{1} M_{3} C_{3}$ through analyzed the range of each influencing factor of Taguchi method. Analyzed the ranking weights of the three schemes for optimization importance, determined the ranking of the schemes and found that $t_{3} p_{1} M_{3} C_{3}$ was the first scheme based on AHP method. What was more, through experimental verification, the experimental and mathematical models had the good consistency. Future studying parameters including anti-erosion properties and wear characteristics must be considered to evaluate the influence of high-quality diamond coating.

\section{ACKNOELEDGEMENTS}


This study was funded by the National Natural Science Foundation of China (grant number 51275358).

\section{REFERENCES}

Alberto, N.J., Simões, R., Nogueira, R.N. and Neto, V.F. 2014.

Optimisation of tailored diamond coating conditions onto optical fibres through the Taguchi method. Diam. Relat. Mat. 43: 60-65. doi:10.101 6/j.diamond.2014.01.014.

Ali, N., Neto, V.F., Mei, S., Cabral, G., Kousar, Y., Titus, E., Ogwu, A.A., Misra, D.S. and Gracio, J. 2004. Optimisation of the new timemodulated CVD process using the Taguchi method. Thin Solid Films 469-470: 154-160. doi:10.1016/j.tsf.2004.08.074.

De Souza, L.P., Gomes, C.F.S. and De Barros, A.P. 2018. Implementation of New Hybrid AHP-TOPSIS-2N Method in Sorting and Prioritizing of an it CAPEX Project Portfolio. Int. J. Inf. Technol. Decis. Mak. 17(04): 977-1005. doi: 10.1142/s0219622018500207.

Ferreira, N. G., Abramof, E., Leite, N. F., Corat, E. J. and Trava-Airoldi, V. J. 2002. Analysis of residual stress in diamond films by x-ray diffraction and micro-Raman spectroscopy. J. Appl. Phys. 91(4): 2466-2472. doi:1 $0.1063 / 1.1431431$.

Jiang, C., Guo, S., Gao, J., Hu, T., Yang, L., Peng, J. and Zhang, L. 2016. Optimization of Growth Parameters for Diamond Films Grown by MPCVD Using Response Surface Methodology. Arab. J. Sci. Eng. 41(7): 2671-2680. doi:10.1007/s13369-016-2169-4.

Li, S. S., Ma, L., Long, H. Y., Yu, X. Y., Luo, H., Wang, Y. J., Zhu, H. K., Yu, Z. M., Ma, M. Y. and Wei, Q. P. 2016. Enhanced electron field emission properties of diamond/microcrystalline graphite composite films synthesized by thermal catalytic etching. Appl. Surf. Sci. 367: 473479. doi:10.1016/j.apsusc.2016.01.195. 
Manivel, D. and Gandhinathan, R. 2016. Optimization of surface roughness and tool wear in hard turning of austempered ductile iron (grade 3) using Taguchi method. Measurement 93: 108-116. doi:10.1016/j.measure ment.2016.06.055.

Sails, S. R., Gardiner, D. J., Bowden, M., Savage, J. and Rodway, D. 1996. Monitoring the quality of diamond films using Raman spectra excited at $514.5 \mathrm{~nm}$ and $633 \mathrm{~nm}$. Diam. Relat. Mat. 5(6-8): 589-591. doi: doi:10.1 016/0925-9635(96)90031-X.

Salgueiredo, E., Amaral, M., Almeida, F.A., Fernandes, A.J.S., Oliveira, F.J. and Silva, R.F. 2013. Mechanical performance upgrading of CVD diamond using the multilayer strategy. Surf. Coat. Technol. 236: 380387. doi:10.1016/j.surfcoat.2013.10.017.

Salgueiredo, E., Amaral, M., Neto, M.A., Fernandes, A.J.S., Oliveira, F.J. and Silva, R.F. 2011. HFCVD diamond deposition parameters optimized by a Taguchi Matrix. Vacuum 85(6): 701-704. doi:10.10 16/j.vacuum.2 010.10.010.

Shen, B., Sun, F.H., Xue, H.G., Chen, M. and Zhang, Z.M. 2013. Study on fabrication and cutting performance of high quality diamond coated PCB milling tools with complicated geometries. Surf. Eng. 25(1): 70-76. doi:10.1179/026708408x334140.

Sherekar, V. and Tatikonda, M. 2016. Impact of factor affecting on labour productivity in construction projects by AHP method. Int. J. Eng. Sci. 6(6): 6771-6775. doi: 10.4010/2016.1619.

Wang, X.C., Lin, Z. C., Shen, B. and Sun, F. H. 2015. Effects of deposition parameters on HFCVD diamond films growth on inner hole surfaces of WC-Co substrates. Trans. Nonferrous Met. Soc. China 25(3): 791-802. doi:10.1016/s1003-6326(15)63665-2.

Wei, Q.P., Yu, Z. M., Ma, L., Yin, D. F. and Ye, J. 2009. The effects of temperature on nanocrystalline diamond films deposited on $\mathrm{WC}-13 \mathrm{wt} . \%$ 
Co substrate with W-C gradient layer. Appl. Surf. Sci. 256(5): 13221328. doi:10.1016/j.apsusc.2009.06.091.

Wind, Y. and Saaty, T. L. 1980. Marketing Applications of the Analytic Hierarchy Process. Manage. Sci., 26(7): 641-658. doi:10.2307/2630699. Yang, T. S., Lai, J. Y., Cheng, C. L. and Wong, M. S. 2001. Growth of faceted, ballas-like and nano-crystalline diamond films deposited in $\mathrm{CH}_{4} / \mathrm{H}_{2} / \mathrm{Ar}$ MPCVD. Diam. Relat. Mat. 10(12): 2161-2166. doi:10.1 016/S0925-9635(01)00495-2.

Yu, B., Wu, S., Jiao, Z. and Shang, Y. 2018. Multi-Objective Optimization Design of an Electrohydrostatic Actuator Based on a Particle Swarm Optimization Algorithm and an Analytic Hierarchy Process. Energy 11(9): 2426. doi:10.3390/en11092426.

Zaidan, A.A., Zaidan, B.B., Alsalem, M.A., Momani, F. and Zughoul, O. 2020. Novel Multiperspective Hiring Framework for the Selection of Software Programmer Applicants Based on AHP and Group TOPSIS Techniques. Int. J. Inf. Technol. Decis. Mak. 19(03): 775-847. doi:1 $0.1142 / \mathrm{s} 0219622020500121$.

Zhang, D., Liu, F. M. and Cai, L.G. 2014. Structure, optical spectra and biaxial stress of (0002) AIN epilayers grown on c-sapphire by hightemperature chemical vapor deposition. Phys. Status Solidi A-Appl. Mat. 211(10): 2394-2402. doi:10.1002/pssa.201431200.

Zhang, J.G., Wang, X.C., Shen, B. and Sun, F. H. 2014. Effect of deposition parameters on micro- and nano-crystalline diamond films growth on WC-Co substrates by HFCVD. Trans. Nonferrous Met. Soc. China 24(10): 3181-3188. doi: 10.1016/s1003-6326(14)63458-0. 